\title{
Flexible PVC-Silica Composites as an Adsorptive Material for Water Soluble Dyes
}

\author{
Sevgi Ulutan ${ }^{1 *}$, Senem Yetgin ${ }^{2}$, and Devrim Balköse ${ }^{2}$ \\ ${ }^{1}$ Ege University, Faculty of Engineering, Dept of Chemical Engineering, 35100, Bornova-Izmir-Turkey \\ ${ }^{2}$ Izmir Institute of Technology, Faculty of Engineering, Dept of Chemical Engineering, Gülbahçe Campus, 35430, Urla- \\ Izmir-Turkey
}

\section{SUMMARY}

\begin{abstract}
Methylene Blue (MB) adsorption studies were performed on flexible Polyvinyl Chloride/Silica composites which were obtained by using plastisol-plastigel technology. Change of MB concentration in aqueous phase as the adsorption process advanced was followed by using visible spectroscopy. The diffusion of MB through the composites exhibited non-Fickian behavior with a diffusivity of $10^{-11} \mathrm{~m}^{2} \mathrm{~s}^{-1}$. Making use of such PVC-silica composite sheets as column packing, the packing time will be reduced and the surface available for diffusion will be increased.
\end{abstract}

Keywords: PVC-silica composites, Methylene Blue, Adsorption, Water soluble dye, Methylene Blue adsorption

\section{INTRODUCTION}

Removal of water soluble dyes from aqueous systems using adsorption is of environmental importance. Basic dyes and methylene blue (MB) are the most studied probe dyes for this purpose. In removal of dyes as well as pure adsorbents, composite materials having adsorbents as dispersed phase are used. Silica $\left(\mathrm{SiO}_{2}\right)$ gel, silica aeroge ${ }^{1}$, highly ordered mesoporous silica structures ${ }^{2}$, diatomaceous silica $^{3}$, luffa fibers ${ }^{4}$, rice hull ash $^{5}$ polyurethane foams ${ }^{6}$ are examples of the pure adsorbents recently used for methylene blue adsorption. Composite materials such as rice husk/silica nanocomposite ${ }^{7}$, activated carbon/ cobalt ferrite, alginate composite beads ${ }^{8}$, humic acid immobilized polymer/bentonite composites ${ }^{9}$, polymer/activated charcoal composites $^{10}$, activated carbon and conducting polymer composites ${ }^{11}$, chitosan based materials ${ }^{12}$, acrylic amide and acrylic acid copolymer and polyvinyl alcohol interpenetrating networks ${ }^{13}$ are the composite materials used for this aim.

Silica gel is one of the good adsorbents for dye adsorption from water, but its colloidal dispersion in water creates turbidity. Embedding silica into a plastic matrix both improves dye absorptivity of the plastic and prevents the contamination of the aqueous phase by silica. Polyvinyl chloride (PVC) is a polymer for dispersing and encapsulating silica gel using different methods. For instance dispersion of silica in PVC could be made by dispersing it in vinyl chloride prior to suspension polymerization ${ }^{14}$. A plasticized PVC with increased porosity has been developed by the use of organic/inorganic hybrids ${ }^{15}$. Melt mixing is another method to prepare $\mathrm{PVC} / \mathrm{SiO}_{2}$ nanocomposites ${ }^{16}$.

*Email: sevgi.ulutan@ege.edu.tr, sevgi.ulutan@gmail.com

${ }^{\circledR}$ Smithers Rapra Technology, 2013

The elasticity of PVC can be controlled by adding plasticizes. Phthalate and non phthalate plasticizers could be used for preparation of flexible PVC materials. Since phthalate plasticizers have undesired health effects nonphthalate plasticizers are preferred recently ${ }^{17}$.

Dioctyl phthalate (DOP) is a well known and versatile plasticizer that could be used in research for flexible PVC preparation.

Thus in the present study composites were prepared by mixing PVC powder, DOP and silica to prepare composites for dye adsorption.

The objective of the present study is to incorporate the adsorption capacity of silica into a plastic matrix so that to obtain a system which has a high capacity for dye adsorption and is convenient to use in ease for column applications ${ }^{18}$ as stacked or pelletized. Therefore, a composite material having silica incorporated into a plastic matrix composed of plasticized PVC with DOP has been produced and characterized in terms of the adsorption behavior. 


\section{METHODS}

\subsection{Materials}

Polyvinyl chloride, PVC, powder (Petvinyl P 38/74, emulsion, <63 $\mu \mathrm{m}$, $1.39 \mathrm{~g} / \mathrm{cm}^{3}$ density, $16 \mathrm{~m}^{2} / \mathrm{g}$ specific surface area, Petkim Co., Turkey), Dioctyl phthalate (DOP, Sankim Co, Turkey), Epoxidized Soybean Oil (ESBO, Akdeniz Kimya Co, Turkey), Calcium Stearate $\left(\mathrm{CaSt}_{2}\right.$, Merck, Germany) Zinc Stearate $\left(\mathrm{ZnSt}_{2}\right.$, Merck), Precipitated Silica (Zeo 49, Huber Corp., USA) are used as they are, to produce composites.

\subsection{Plastisol and Composite Preparation}

A hundred g PVC and $60 \mathrm{~g}$ DOP, $5 \mathrm{~g} \mathrm{ESBO}^{2} 2.75 \mathrm{~g} \mathrm{CaSt}_{2}$ and $0.275 \mathrm{~g}$ $\mathrm{ZnSt}_{2}$ were mixed and a homogeneous plastisol was obtained by stirring at $200 \mathrm{rpm}$ in a laboratory type dough kneader. Small aliquots of plastisol mixed with $2,4,8,12$ and, $16 \%$ in mass silica powder, in a porcelain mortar with a porcelain handle. The entrapped air in the plastisol and composites were removed by means of vacuum.

\subsection{Sheet Preparation}

Gelation of the above plastisol at $140 \pm 2{ }^{\circ} \mathrm{C}$ for 16 minutes, between A316 stainless steel plates under $5 \mathrm{MPa}$ pressure in a hot press led to the formation of plastic sheets of 314$560 \mu \mathrm{m}$ thick. The sheets were taken out of the press after cooling down to $40^{\circ} \mathrm{C}$.

\subsection{Morphological Studies}

The SEM microphotographs of the gold coated PVC powder and silica were obtained with ETD technique by using Philips XL 30 S FEG and QUANTA 250F SEM instrument, respectively. SEM microphotographs of the gold coated fracture surfaces obtained immersing the sheets in liquid nitrogen were taken by using QUANTA 250F SEM instrument using both secondary electron (ETD) and backscattering electron (BSED) techniques.

\subsection{Water Sorption of Composites}

Strips of sheets were immersed in pure water for two weeks and they were weighed after removing them from water and blotting with tissue paper.

\subsection{Adsorption Isotherm Measurement}

Equilibrium uptakes from $0.018 \mathrm{~g}$ $\mathrm{dm}^{-3} \mathrm{MB}$ solution by PVC composites without silica and with $16 \%$ silica, $\mathrm{PVC}$ and silica powders were determined at $25{ }^{\circ} \mathrm{C}$ measuring $\mathrm{MB}$ solution concentrations by using Jasco 7800 UV - Vis spectrophotometer. All MB containing solutions were kept in dark to prevent the attack of sunlight.

\subsection{Adsorption Rate Experiment}

On liquid side: Ten PVC composite pellets having $0-16 \%$ silica were immersed in $50 \mathrm{~cm}^{3} 0.018 \mathrm{~g} \mathrm{dm}^{-3} \mathrm{MB}$ solutions. $5 \mathrm{~cm}^{3}$ solution and one pellet were taken out of the flask at each time, to keep the solid/liquid ratio unchanged during adsorption. MB concentration in the liquid phase was measured by means of visible spectroscopy.

On solid side: The plastigel and the composite sheets were equilibrated with $0.04 \mathrm{~g} \mathrm{dm}^{-3} \mathrm{MB}$ solution. The visible spectra of MB adsorbed sheets were taken by using transmission technique in Perkin Elmer 3 UV- visible spectrophotometer. The microphotographs of the sheets were taken with transmission technique, using Olympus, CH40 microscope.

Figure 1. SEM micrographs of (a) PVC powder, (b) Silica powder

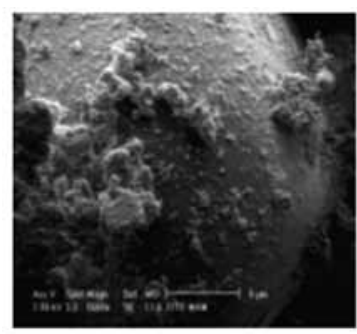

\section{RESULTS AND DISCUSSION}

Flexible PVC-silica composites, having a porous structure were produced by using plastisol-plastigel technology. While equilibrium uptake evaluations were performed through visible spectroscopy and optical microphotography studies, a kinetic study was performed for the MB adsorption of composites, as well.

\subsection{PVC and Silica Powders}

The morphologies of PVC and silica powders are seen in Figure 1. PVC powder has a large particle size distribution. The spherical particles had a wide range of size distribution. Silica powder particles were agglomerated and smaller in size than PVC particles. The average particle size of PVC particles was reported as $9 \mu \mathrm{m}^{19}$.

The density, the surface area, and the pore volume of silica were $1.58 \mathrm{~g}$ $\mathrm{cm}^{-3}, 148 \mathrm{~m}^{2} \mathrm{~g}^{-1}$ and, $0.12 \mathrm{~cm}^{3} \mathrm{~g}^{-1}$, respectively.

\subsection{Structure of Composites}

PVC plastisols are gelled by swelling of PVC particles with the plasticizer, fusion and crosslinking of the swollen particles to each other during heating. A mesoporous silica was dispersed in plastisols by mixing before gelation process. The plastisols were gelled by heating at $140{ }^{\circ} \mathrm{C}$. This temperature was chosen, since PVC was not thermally stable at higher temperatures. 
The morphology of the composite films having 12 and $16 \%$ silica are shown in Figure 2. As seen in the Figure silica particles are embedded in continuous phase of plasticized PVC and they created a porous structure.

The density of the flexible composite sheets of 314 - $563 \mu \mathrm{m}$ thickness, as measured by using water in a glass pycnometer, increased from 1.098 to $1.231 \mathrm{~g} / \mathrm{cm}^{3}$ as the silica content increased. The sheets had up to $7.3 \%$ empty volume which could be attributed incomplete air removal due to high viscosity of the plastisol. The composites absorbed 1.92 to $6.07 \%$ water from liquid water as their silica content increased $^{20}$.

\subsection{MB Adsorption Isotherm}

The adsorption isotherms of $\mathrm{MB}$ on silica and the composite having $16 \%$ silica are shown in Figure 3.

The adsorption isotherms fitted to Langmuir model shown by Equation(1).

$$
1 / \mathrm{Q}=1 / \mathrm{Q}_{\mathrm{m}}+\mathrm{C} /\left(\mathrm{Q}_{\mathrm{m}} \mathrm{K}\right)
$$

Where:

$\mathrm{K}=$ Langmuir constant $\left(\mathrm{dm}^{3} \mathrm{mg}^{-1}\right)$

$\mathrm{Q}_{\mathrm{e}}=\mathrm{MB}$ concentration at equilibrium in powder $\left(\mathrm{mg} \mathrm{g}^{-1}\right)$

$\mathrm{C}_{\mathrm{e}}=\mathrm{MB}$ concentration at equilibrium in solution $\left(\mathrm{mg} \mathrm{dm}^{-3}\right)$,

$\mathrm{Q}_{\mathrm{m}}=\mathrm{MB}$ concentration when monolayer forms onto particle surface $\left(\mathrm{mg} \mathrm{g}^{-1}\right)$.

PVC in powder form also adsorbed methylene blue and the adsorption isotherm was represented by Langmuir model $^{19}$.

Table 1 shows the Langmuir constants of silica, PVC powder and $16 \%$ silica film.

The adsorption capacity of a composite material is predicted from the adsorptivity of components by using the "additivity rule" in Equation (2) ${ }^{21}$

Figure 2. SEM micrographs of films with (a) $16 \%$ silica with ETD, (b) $16 \%$ silica with BSED, (c) $12 \%$ silica with ETD, and (d) $12 \%$ silica with BSED
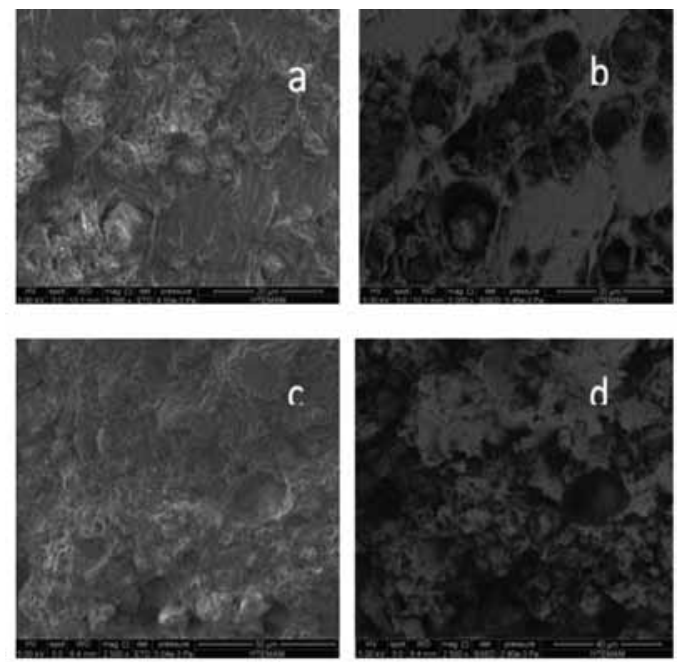

Figure 3. MB Adsorption isotherms of silica (spheres), composite with $13 \%$ silica experimental (triangles), theoretical (square)

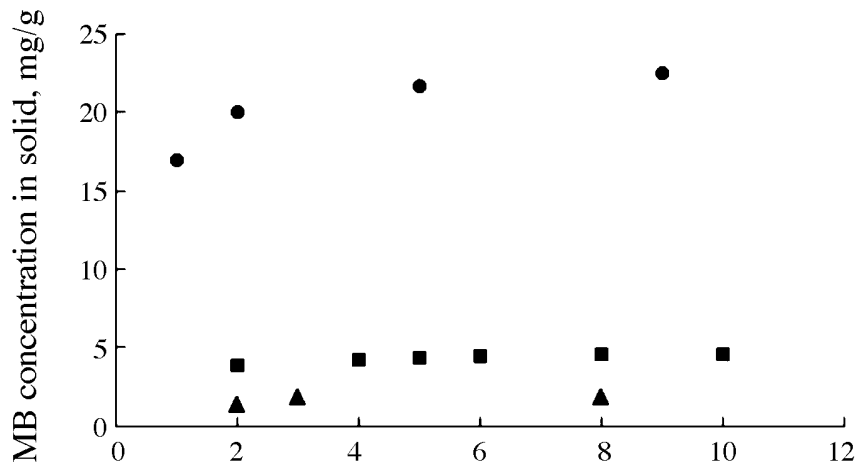

MB concentration in water, $\mathrm{mg} / \mathrm{dm}^{3}$

Table 1. Langmuir isotherm constants of the adsorption isotherm of MB on silica powder, $\mathrm{PVC}_{\text {powder }}{ }^{19}$ and $13 \% \mathrm{SiO}_{2}$ composite

\begin{tabular}{|l|c|c|}
\hline Sample & $\mathbf{Q}_{\mathbf{m}}$ & $\mathbf{K}$ \\
\hline Silica & 23.54 & 2.7 \\
\hline PVC powder & 6.18 & 1.36 \\
\hline $16 \% \mathrm{SiO}_{2}$ composite & 2.22 & 0.97 \\
\hline
\end{tabular}

$\mathrm{Q}_{\mathrm{c}}=\Sigma \mathrm{Q}_{\mathrm{i}} \times \mathrm{m}_{\mathrm{i}}$

Where, $Q_{c}$ and $Q_{i}$ are the amount of mass adsorbed on unit mass of the composite and its components, respectively, and $\mathrm{m}_{i}$ is the mass fraction of each component in composite structure.
When PVC was dissolved in DOP, the surface area is reduced and its MB adsorption capacity gets lowered. Also encapsulating silica in the polymer matrix reduced the adsorption capacity. In Figure 3 the experimental adsorption isotherms of composite with 
Figure 4. Change of MB concentration in composites with their silica content for initial $\mathrm{MB}$ concentration of $18 \mathrm{mg} \mathrm{dm}^{-3}$ in water

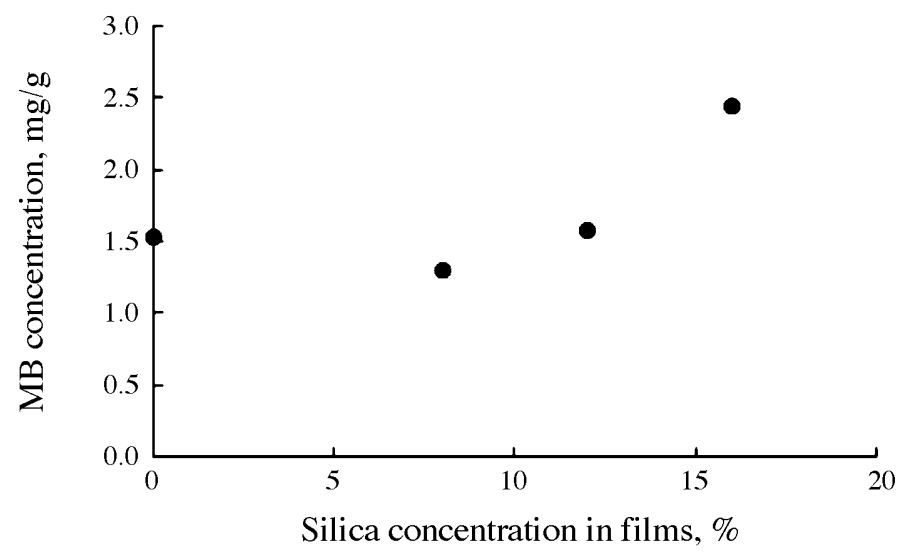

Figure 5. Change of MB concentration with time for initial MB concentration of $18 \mathrm{mg} / \mathrm{dm}^{3}$ for composites having different concentrations of silica

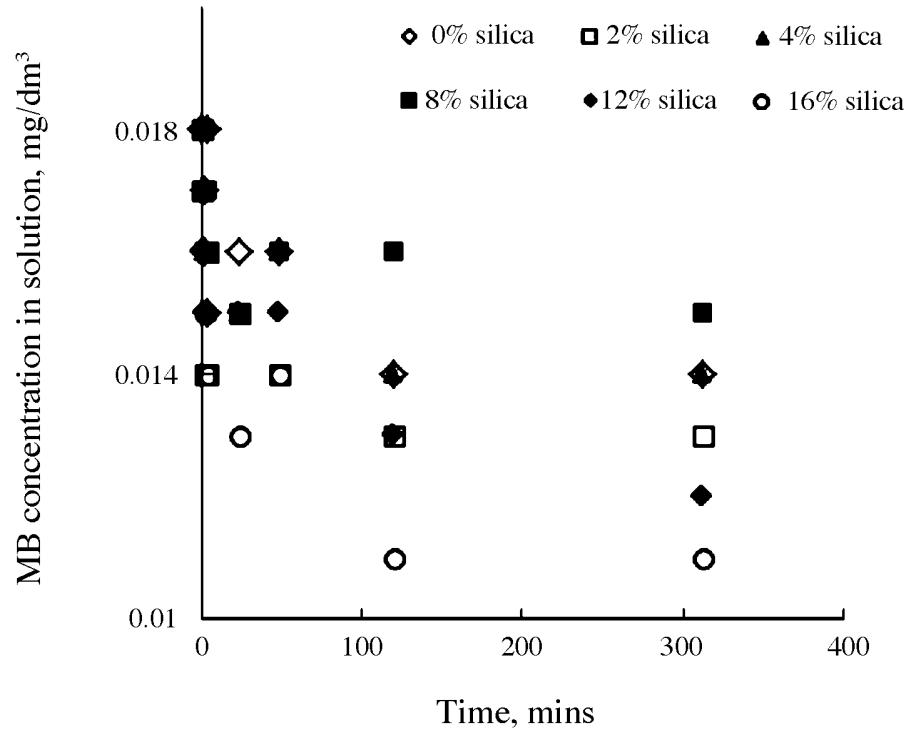

Figure 6. Change of fractional uptake with square root of time

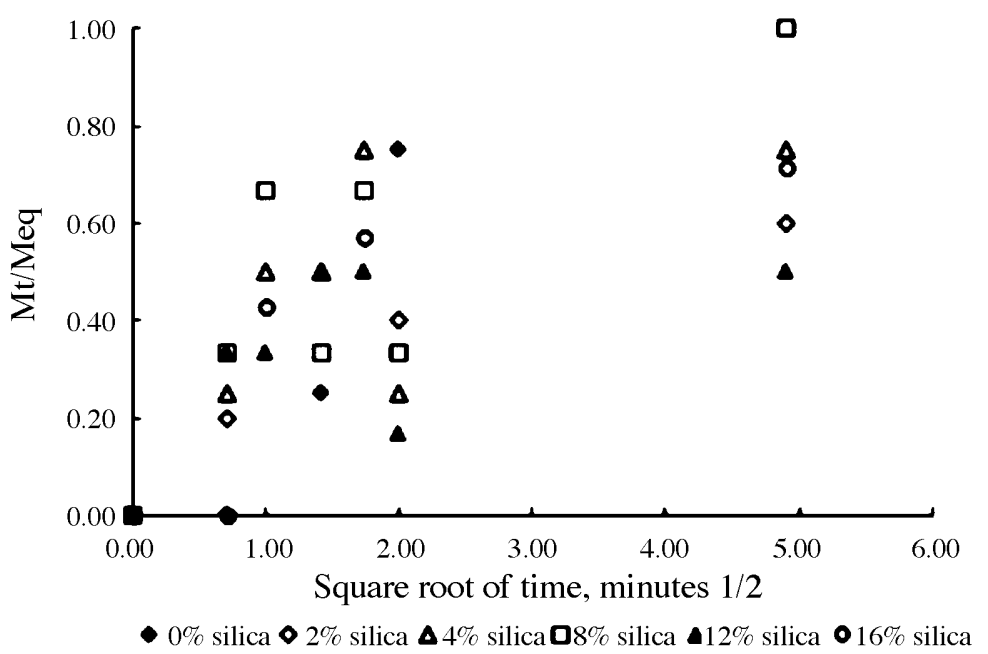

$12 \%$ silica and predicted values from Equation (3) are shown. However the composites having silica had higher $\mathrm{MB}$ adsorption capacity as seen in Figure 4.

\subsection{MB Adsorption Kinetics}

As the MB adsorption process progresses, $\mathrm{MB}$ concentration in the solution phase diminishes as seen in Figure 5.

The coefficient of diffusion of MB in composites can be obtained carrying out the procedure of classical methods as if the process were Fickian. Equation (3) was used for the evaluation of short time data of adsorption to find out the effective diffusion coefficient.

$$
\mathrm{M}_{\mathrm{t}} / \mathrm{M}_{\mathrm{eq}}=(4 / \mathrm{l})\left(\mathrm{D}_{\mathrm{e}} \mathrm{t} / \pi\right)^{0.5}
$$

Where, $M_{t}$ and $M_{e q}$ are the adsorbed amount at time $\mathrm{t}$ and at equilibrium respectively, $l$ is the diffusion path length, and, $D_{e}$ is the effective diffusion coefficient.

As seen in Table 2 the diffusivity of $\mathrm{MB}$ in composites is at the order of $10^{-11} \mathrm{~m}^{2} / \mathrm{s}$. They exhibit almost the same order of the diffusion coefficient of MB in PVC natural zeolite composites ${ }^{22}$. The regression coefficients of the linear relations represented by Equation (3) was low (Table 2) due to oscillating nature of the adsorption process. The composite without any silica had a higher MB diffusion coefficient since the MB moved in composite without being absorbed.

The objective of the present study is to incorporate the adsorption capacity of silica into a plastic matrix so that to obtain a system which has a high capacity for dye adsorption and is convenient to use in ease for column applications ${ }^{18}$ as stacked or pelletized. Using such PVC-silica composite sheets as column packing, the packing time will be reduced and the surface available for diffusion will be increased ${ }^{18}$. Therefore, a composite 
Table 2. Methylene blue adsorbed at equilibrium for initial MB concentration of $0.018 \mathrm{~g} / \mathrm{dm}^{3}$ and solid liquid ratio of $0.03 \mathrm{~g} /$ $\mathbf{c m}^{3}$, Diffusion coefficient of the films and their regression coefficient

\begin{tabular}{|c|c|c|c|}
\hline Silica Conc. $\%$ & $\mathbf{q}_{\mathbf{e}}, \mathbf{m g} / \mathbf{g}$ & $\mathbf{D}$ of $\mathbf{M B ~ x 1 0} \mathbf{1 1}^{\mathbf{1 1}} \mathbf{~ m}^{\mathbf{2}} \mathbf{g}$ & $\mathbf{R}^{\mathbf{2}}$ for $\mathbf{D}$ \\
\hline 0 & 1.54 & 14.6 & 0.74 \\
\hline 2 & 2.29 & 1.5 & 0.84 \\
\hline 4 & 1.99 & 2.5 & 0.16 \\
\hline 8 & 1.29 & 4.5 & 0.40 \\
\hline 12 & 1.57 & 4.2 & -0.34 \\
\hline 16 & 2.43 & 3.3 & 0.60 \\
\hline
\end{tabular}

material having silica incorporated into a plastic matrix composed of plasticized PVC with DOP has been produced and characterized in terms of the adsorption capacity of the system which is a prospective material for dye adsorption.

\section{CONCLUSIONS}

Plastisol-plastigel technique provides a simple and inexpensive method to produce the flexible PVC-silica composite sheets as column packing for the removal of colored contaminants of industrial waste waters. Although the MB adsorption capacity was extensively high for silica, it was moderate for the composite most likely due to the occlusion of pores of silica by plasticizer to some extent. While the silica component provides high adsorption capacity, PVC matrix keeps the silica particles coherent and hinders the contamination of the solution with dispersed silica. $90 \%$ clarification of a $0.02 \mathrm{gdm}^{-3} \mathrm{MB}$ solution was achieved through the use of $16 \%$ silica containing composite for the solid liquid ratio of $0.12 \mathrm{~g} / \mathrm{cm}^{3}$. Since silica component is the main adsorbing site, the more the silica is added into the composite, the higher is the adsorption capacity to be introduced. The apparent diffusivity of the present composites was at the order of $10^{-11} \mathrm{~m}^{2} / \mathrm{s}$. Making use of such PVC-silica composite sheets as column packing, the packing time will be reduced and the surface available for diffusion will be increased.

\section{REFERENCES}

1. $\quad$ Liu G.Q., Yang R., et al., Journal of Non-Crystalline Solids, 356 (2010) 250-257.

2. Anbia M. and Hariri S.A., Desalination, 261 (2010) 61-66.

3. Al-Qodah Z., Lafi W.K., et al., Desalination, 217 (2007) 212-224.

4. Demir H., Top A., et al., Journal of Hazardous Materials, 153 (2008) 389-394.

5. Chen X.G., Lv S.S., et al., Separation Science and Technology, 47 (2012) 147-156.

6. Neta J.D.D., Moreira G.C., et al., Desalination, 281 (2011) 55-60.

7. Adam F., Appaturi J.N., et al., Applied Surface Science, 264 (2013) 718-726.

8. Ai L.H., Li M., et al., Journal of Chemical and Engineering Data, 56 (2011) 3475-3483.

9. Anirudhan T.S., Suchithra P.S., et al., Applied Clay Science, 43 (2009) 336-342.

10. Bajpai S.K. and Shrivastava S., Journal of Applied Polymer Science, 119 (2011) 2525-2532.

11. Baseri J.R., Palanisamy P.N., et al., E-Journal of Chemistry, 9 (2012) 1122-1134.
12. Guo R. and Wilson L.D., Journal of Colloid and Interface Science, $\mathbf{3 8 8}$ (2012) 225-234.

13. Zendehdel M. and Barati A., et al., Iranian Journal of Environmental Health Science \& Engineering, 7 (2010) 423-428

14. Georgiadou S., Jin L., Thomas N.L., Gilbert M., and Brooks B.W., Journal of Applied Polymer Science,124 (2012) 1824-1830.

15. Gilbert M., Haghighat S., Chua S.K, and Ng S.Y., Macromolecular Symposia, 233 (2006) 198-202.

16. Ari G.A. and Aydin I., Polymer Engineering and Science, 51 (2011) 1574-1579.

17. Tuzum Demir A.P, Ulutan S, $J$. Appl. Polym. Scl., 128 (2013) 19481961.

18. Goldberg B., Bioprocess Eng. Symp., ASME BED V 21 (1991) 73.

19. Savrik S.A., Balkose D., Ulutan S., and Ulku S., J. Therm. Anal. Calorim., 101 (2010) 801-806.

20. Ulutan S. and Balköse D., Composite Interfaces, 4 (1996) 223-237.

21. Marshall R.A., J. Vinyl Tech., 12 (1990) 195-197.

22. Balköse D., Ulutan S., Özkan F., Ülkü S, and Köktürk U., Sep. Sci. Technol., 31 (1996) 1279-1289. 
Copyright of Polymers \& Polymer Composites is the property of Rapra Technology and its content may not be copied or emailed to multiple sites or posted to a listserv without the copyright holder's express written permission. However, users may print, download, or email articles for individual use. 